\title{
EDITORIAL
}

\section{Examination Stress in Medical Career}

\author{
MAHDY ZA, SRIJIT D \\ ${ }^{1}$ Department of Obstetrics and Gynaecology, ${ }^{2}$ Department of Anatomy, Faculty of \\ Medicine, Universiti Kebangsaan Malaysia Medical Centre, Jalan Yaacob Latif, Bandar \\ Tun Razak, 56000 Cheras, Kuala Lumpur, Malaysia.
}

Examination in any medical career has never been easy. Even after passing an examination in one's medical career, one may still harbor nightmares and wake up with fright in the middle of the night. Rigorous examinations in the medical field require a lot of courage and resilience. Unfortunately, many succumb to mental illness.

Stress is natural and certain to happen in any individual before any unnerving event. Examinations in medical career are no exception. According to the Health and Safety Executive, United Kingdom, work related stress was one of the main reasons for all new incidences of ill health. Approximately, 13.5 million working days were lost during the year 2007-2008 due to work related stress, depression and anxiety (Janes, 2006). According to researchers, young medical doctors suffer from high levels of stress and distressing conditions, which are mostly related to training during their medical career, rather than pertaining to individual psychological capabilities (Tartas et al. 2016).

For some individuals, even studying and attending wards regularly in medical career is considered stressful. Few individuals can face stress while discharging their daily activities. On several occasions, the syllabus is not properly covered on time resulting in last minute stress prior to examinations. At times, students cannot cope with stress prior to examinations and even decide to skip examinations. There are students who experience thought block during examinations, panic and commit silly mistakes. Interestingly, it was found that those individuals who avoid coping strategies, are always at risk of developing mental health problems later in life (Stewart et al. 1997).

Stress is handled well once an individual seeks proper support and help. It is more risky in individuals who seldom socialize and stay in isolation. A stressful condition also precipitates underlying problems in personal life. According to Dr Wolfgang Seidl, executive director of The Validium Group, who specialises in management consultancy, psychotherapy and stress management, "our reactions to stress

Address for correspondence and reprint requests: Zaleha Abdullah Mahdy. Department of Obstetrics and Gynaecology, Faculty of Medicine, Universiti Kebangsaan Malaysia Medical Centre, Jalan Yaacob Latif, Bandar Tun Razak, 56000 Cheras, Kuala Lumpur, Malaysia. Tel: +603 91455954 E-mail: zaleha@ppukm. ukm.edu.my 
are very much personal" (Janes, 2006). Hence, different individuals may have different perceptions. It is always advisable to have good hobbies, extracurricular activities and inclination for sports in order to ease pre-examination stress.

We feel that proper monitoring of medical students is essential. In this regard, our institution has even provided a mentor-mentee system which detects any peculiar behaviour by the student. Proper counselling is also provided. Our only aim is to stop and check the unnecessary dropouts as it is a big blow to the nation if a doctor fails to be produced.

A medical student has to be convinced that the examination procedures may be tedious but at the same time quite easy if study is done regularly instead of piling up at the last minute. A high self-esteem needs to be developed and the students need to be advised to remain positive in their outlook in life. Having mock examinations may help a lot to relieve the stress. If we nurture our students as we would our own sons and daughters, there is no reason why success rate in examinations in medical career cannot improve.

Perhaps, before any examination we must always remind our students what Dr. Benjamin Spock, an American Paediatrician, said: "Trust yourself, you know more than you think you do."

\section{REFERENCES}

Janes, C. The joy of stress. BMJ Careers. Website: http://careers.bmj.com/careers/advice/viewarticle.html?id=20000140. Last accessed on 3.6.2018.

Stewart, S.M., Betson, C., Lam, T.H., Marshall, I.B., Lee, P.W., Wong, C.M. 1997. Med Educ 31(3): 163-8.

Tartas, M., Walkiewicz, M., Budziński, W., Majkowicz, M., Wójcikiewicz, K., Zdun-Ryżewska, A. 2016. The coping strategies during medical education predict style of success in medical career: a 10-year longitudinal study. BMC Medical Education 16: 186.

Received: 31 May 2018

Accepted: 5 June 2018 